\section{A integralidade na prática (ou sobre a prática da integralidade)}

\author{
Comprehensiveness in practice \\ (or, on the practice of comprehensiveness)
}

\footnotetext{
1 Instituto de Medicina Social, Universidade do Estado do Rio de Janeiro, Rio de Janeiro, Brasil.

Correspondência

R. A. Mattos

Instituto de Medicina Social, Universidade do Estado do Rio de Janeiro. Rua São Francisco Xavier 524, 7o andar,

Rio de Janeiro, $R J$ 20559-900, Brasil. ruben@ims.uerj.br
}

\begin{abstract}
This article reflects on the manifestations or signs of comprehensiveness in health practice, seeking to facilitate recognition of experiences that are advancing in this direction and allowing them to be analyzed subsequently. The article is also intended to spawn increasing involvement by actors in practices based on comprehensiveness. The point of departure is the principle that what characterizes comprehensiveness is an expanded grasp of the needs and ability to recognize the adequacy of the health care supply in the specific context where the subject meets the health team; in addition, to foster comprehensiveness means defending the notion that health actions be attuned to the specific context of each encounter.
\end{abstract}

Comprehensive Health Care; Professional Practice; Health Services

\section{Introdução}

O termo integralidade tem sido usado para designar um dos princípios do Sistema Único de Saúde (SUS). Mais do que isso, ele expressa uma das bandeiras de luta do chamado movimento sanitário. De certo modo, ele tem funcionado como uma imagem-objetivo, ou seja, como uma forma de indicar (ainda que de modo sintético) características desejáveis do sistema de saúde e das práticas que nele são exercidas, contrastando-as com características vigentes (ou predominantes). Mas caberia perguntar: integralidade segue sendo uma noção (ou um conjunto de noções) útil para identificar certos valores e características que julgamos desejáveis no nosso sistema de saúde? Ele ainda segue sendo um bom indicador da direção que desejamos imprimir ao sistema e às suas práticas? Ele segue sendo útil como indicador, por contraste, das características que criticamos no sistema de saúde e nas suas práticas?

Partindo da hipótese de que podemos dar uma resposta afirmativa a estas perguntas, em trabalho anterior 1 realizamos uma investigação sobre os diversos sentidos do termo integralidade no contexto da luta pela reforma sanitária no Brasil. Identificamos pelo menos três conjuntos de sentidos. Um primeiro aplicado a características de políticas de saúde ou de respostas governamentais a certos problemas de saúde. Aqui, a integralidade se referia sobretu- 
do à abrangência dessas respostas governamentais, no sentido de articular ações de alcance preventivo com as assistenciais. Um segundo conjunto de sentidos era relativo a aspectos da organização dos serviços de saúde. Um terceiro era voltado para atributos das práticas de saúde. Ocupo-me neste texto fundamentalmente desse último conjunto de sentidos, embora também tangenciaremos alguns dos sentidos relativos à organização dos serviços.

Dentre os princípios e diretrizes do SUS, talvez o da integralidade seja o que é menos visível na trajetória do sistema e de suas práticas. Com efeito, são evidentes as mudanças do sistema tanto no eixo da descentralização quanto no do controle social. No que diz respeito ao acesso universal, no SUS atualmente já não há as barreiras formais que limitavam o acesso apenas aos que contribuíam para a previdência social. É claro que são ainda inúmeras as barreiras de acesso que privam brasileiros das ações e serviços de saúde que necessitam, de modo que ainda temos muito de caminhar no sentido da igualdade do acesso.

Mas no que diz respeito à integralidade, as mudanças não têm sido tão evidentes. Elas acontecem aqui e acolá, mas ainda não ganharam a generalização nem a visibilidade que almejamos. Exatamente por isso, talvez seja oportuno dedicar maior atenção ao exame dessas experiências, em sua maioria localizada, que transformam as práticas na direção da integralidade. Há que reconhecê-las, analisar as condições que tornaram possível sua emergência, refletir sobre os potenciais e os limites de sua difusão. Analisar as experiências que se pautam pela integralidade é uma importante agenda de pesquisa.

Este texto pretende oferecer subsídios para essa agenda de investigação, ao refletir sobre as diversas dimensões que a integralidade pode assumir (e talvez esteja assumindo) nas práticas em saúde. Não se trata ainda de um trabalho empírico, no sentido que aqui nenhuma experiência concreta é analisada. Trata-se antes, de uma reflexão sobre as manifestações ou os signos da integralidade na prática em saúde, feita com um duplo propósito: o de facilitar o reconhecimento de experiências que estejam avançando no que diz respeito à integralidade, permitindo que elas sejam posteriormente analisadas; o de contribuir para que cada vez mais atores se engajem na construção de práticas pautadas pela integralidade.

\section{Integralidade e o acesso universal e igualitário às ações e serviços de saúde}

Na literatura, encontramos alguns textos que tratam a noção de integralidade como se a mesma fosse sinônima da garantia de acesso a todos os níveis do sistema de serviços de saúde. Talvez essa leitura da integralidade seja um bom ponto de partida de nossa reflexão.

O texto da Constituição brasileira afirma ser dever do Estado garantir "o acesso universal e igualitário aos serviços de saúde para sua promoção, proteção e recuperação". Nesse mesmo texto, o que chamamos de integralidade aparece como um dos princípios do SUS: “atendimento integral, com prioridade para as atividades preventivas, sem prejuízo dos serviços assistenciais". Ambos os trechos têm em comum o fato de articularem diversas dimensões ou lógicas das ações e dos serviços de saúde: promoção, proteção e recuperação, no primeiro, e atividades preventivas e assistenciais, no segundo.

O SUS pode ser visto como um dispositivo institucional criado pelo governo para dar conta do seu dever de garantir o acesso universal e igualitário nos termos da Constituição. Ele foi concebido como abarcando todas as ações e serviços públicos de saúde (assim como alguns serviços privados). Estes deveriam estar organizados como uma rede regionalizada e hierarquizada. A noção de hierarquização pressupõe o estabelecimento de certos níveis de atenção (chamemos assim). Para delimitar esses níveis de atenção, é necessário dispor os diferentes recursos tecnológicos existentes para a promoção, a proteção ou a recuperação da saúde (ou as tecnologias voltadas para a prevenção) nos diversos tipos de serviços de saúde. É desses níveis de atenção que falamos quando defendemos que todos os brasileiros possam ter assegurado seu acesso a todos os níveis.

É claro que existem várias possibilidades para os critérios utilizados nessa disposição das tecnologias nos diferentes níveis de atenção. No Brasil, por exemplo, adotou-se uma definição de atenção básica bastante centrada nas necessidades dos diversos grupos populacionais: " a atenção básica pode ser compreendida como um conjunto de ações, de caráter individual ou coletivo, situadas no primeiro nível de atenção dos sistemas de saúde, voltadas para a promoção da saúde, prevenção de agravos, tratamento e reabilitação...” 2 (p. 5).

Note-se que nessa definição, a atenção básica se ocupa tanto de ações preventivas como assistenciais. O seu conteúdo, dinâmico, é ditado pelo conjunto de situações e problemas 
de saúde mais freqüentes numa certa população. Analogamente, os outros níveis de atenção também se ocupam (ou devem se ocupar) tanto da prevenção como da assistência.

Portanto, uma coisa é defender o acesso universal e igualitário às ações e serviços de saúde que se façam necessários, o que, numa rede regionalizada e hierarquizada, pode assumir a forma da defesa ao acesso a todos os níveis de atenção do sistema de saúde. Outra coisa, igualmente importante, é defender que em qualquer nível haja uma articulação entre a lógica da prevenção (chamemos por hora assim) e da assistência, de modo que haja sempre uma apreensão ampliada das necessidades de saúde.

É por esta razão que talvez seja útil não considerar integralidade como sinônimo do acesso a todos os níveis do sistema. O que nos remete a aprofundar a reflexão sobre as características das práticas que se pautam pela integralidade.

\section{Sobre a articulação entre a assistência e prevenção}

Uma das críticas mais recorrentes ao arranjo das práticas de saúde predominantes diz respeito à ênfase à assistência. De fato, nos anos setenta, o antigo sistema de saúde se estruturou de modo polar: de um lado, o Instituto Nacional de Assistência Médica da Previdência Social (INAMPS) se ocupou das ações assistenciais, organizando os serviços para responder a demanda espontânea; de outro, o Ministério da Saúde naquele arranjo deveria se ocupar daquelas outras necessidades de saúde pública. Indiscutivelmente tal arranjo não favorece a melhoria da saúde da população. A criação do SUS modificou esse arranjo institucional, mas não necessariamente transformou as práticas dos serviços, de modo a articular a prevenção e a assistência, como diz o texto constitucional.

Em que a lógica assistencial se distancia da lógica da prevenção? Se tomarmos por um momento a perspectiva da atenção às pessoas, podemos constatar que a assistência é demandada a partir de uma experiência de sofrimento e de uma leitura de ser possível encontrar alento para tal sofrimento num serviço de saúde. Isso resulta no que chamamos de "demanda espontânea”. Obviamente, tanto a experiência de sofrimento como essa expectativa frente aos serviços de saúde são construídas socialmente, embora experimentadas individualmente, o que nos leva à conclusão de que essa demanda que parece ser espontânea de fato é construída socialmente. Mas aqui o que importa é que a as- sistência vincula-se a uma experiência individual de sofrimento.

Já as ações preventivas se antecipam à experiência individual de sofrimento. Elas atuam ainda no silêncio dos órgãos. Elas são possíveis porque nosso conhecimento sobre as doenças (que causam alguns sofrimentos) permitiu antever riscos ou mesmo reconhecer precocemente a doença antes mesmo que ela gere qualquer sofrimento. Portanto, a necessidade de uma ação preventiva é ditada a partir do conhecimento dos profissionais. Ela é de certo modo ofertada pelos profissionais de saúde.

Uma primeira dimensão da integralidade, na prática se expressa exatamente na capacidade dos profissionais para responder ao sofrimento manifesto, que resultou na demanda espontânea, de um modo articulado à oferta relativa a ações ou procedimentos preventivos. Para os profissionais, isso significa incluir no seu cotidiano de trabalho rotinas ou processos de busca sistemática daquelas necessidades mais silenciosas, posto que menos vinculadas à experiência individual do sofrimento. Para os serviços, isso significa criar dispositivos e adotar processos coletivos de trabalho que permitam oferecer, para além das ações demandadas pela própria população a partir de experiências individuais de sofrimento, ações voltadas para a prevenção.

Aprofundemos um pouco mais essa questão: não se trata de simplesmente desenvolver protocolos ou rotinas capazes de identificar e oferecer ações preventivas não demandadas diretamente pelas pessoas que procuram os serviços de saúde. Há que se compreender o contexto específico de cada encontro entre membros da equipe de saúde e as pessoas. Há que se adotar uma postura que identifica a partir do conhecimento técnico as necessidades de prevenção e as assistenciais, e que seleciona as intervenções a serem ofertadas no contexto de cada encontro.

Por exemplo, imaginemos um homem obeso, com vida sedentária, fumante inveterado, que procura ser prontamente atendido por apresentar forte dor lombar provocada por um cálculo renal. É claro que no momento em que procura o serviço de saúde, nem ele nem os profissionais sabem que seu sofrimento se deve a litíase renal. A equipe que o atende, na perspectiva da integralidade, deve ser capaz de identificar a doença que causa o sofrimento manifesto, dar uma resposta imediata à dor, e reconhecer a necessidade de uma conversa sobre os fatores de risco de doenças cardiovasculares e pulmonares que o paciente apresenta. Mas note-se que, nessa situação hipotética, não é acei- 
tável que a conversa sobre a vida sedentária ocorra antes que as medicações capazes de eliminar a dor surtam seu efeito. A integralidade se manifesta aqui na postura de não aceitar a redução da necessidade de ações e serviços de saúde à necessidade de identificar e dar resposta para a doença que suscita o sofrimento manifesto (e, nesse caso, a procura ao serviço de saúde). Isso envolve duas coisas: uma apreensão ampliada das necessidades do sujeito, que englobe tanto as ações de assistência como as voltadas para a prevenção de sofrimentos futuros; e uma capacidade de contextualizar adequadamente as ofertas a serem feitas àquele sujeito, de modo a identificar os momentos propícios a tal oferta.

Um outro exemplo: se uma mulher de vinte anos procura um serviço de saúde por ter sido vítima de estupro na véspera, obviamente ela precisa antes de mais nada ser acolhida. A conversa deverá necessariamente tratar da oferta da contracepção de emergência, assim como das medidas de intervenção frente à possibilidade de adquirir doenças sexualmente transmissíveis como a infecção por HIV. Mas seria absurdo que os profissionais começassem uma conversa sobre a necessidade das práticas de sexo seguro. Ou seja, o que caracteriza a integralidade é obviamente a apreensão ampliada das necessidades, mas principalmente essa habilidade de reconhecer a adequação de nossas ofertas ao contexto específico da situação no qual se dá o encontro do sujeito com a equipe de saúde.

Um outro exemplo, esse real: uma agente comunitária que fazia visitas domiciliares com a finalidade de acompanhar a evolução do peso das crianças menores de dois anos, inscritas num programa de distribuição de leite (tratava-se do antigo Incentivo às Carências Nutricionais), e que tinha uma rotina a ser cumprida em cada visita, ao entrar num casebre, vê de imediato um homem "jogado" dormindo numa velha poltrona e as marcas da fivela de um cinto nos braços de uma das crianças da casa. Imediatamente, a agente abandona sua rotina e, conversando em voz baixa para não acordar o homem, estabelece uma conversa (na verdade uma negociação) com a mãe das crianças sobre as providências que deveriam ser tomadas para proteger mãe e crianças da violência do marido e pai ${ }^{3}$. Trata-se de um exemplo de uma postura de integralidade. Aqui, como nos demais exemplos, o princípio da integralidade é exercido por meio de um olhar atento, capaz de apreender as necessidades de ações de saúde no próprio contexto de cada encontro.

Não importa em que contexto ocorre o encontro entre as pessoas e os membros da equi- pe de saúde. A possibilidade de articular ações preventivas e assistenciais envolve um duplo movimento por parte dos profissionais. De um lado, apreender de modo ampliado as necessidades de saúde. De outro, analisar o significado para o outro das demandas manifestas e das ofertas que podem ser feitas para responder as necessidades apreendidas, tendo em vista tanto o contexto imediato do encontro como o contexto da própria vida do outro, de modo a selecionar aquilo que deve ser feito de imediato e gerar estratégias de produzir novos encontros em contextos mais adequados àquelas ofertas impertinentes no contexto específico daquele encontro. $\mathrm{O}$ que nos remete à questão da contextualização.

\section{Integralidade como uma apreensão ampliada e prudente das necessidades de ações e serviços de saúde}

Do que dissemos antes, emerge uma compreensão que perpassa os diversos sentidos da integralidade que se referem aos encontros entre equipe de saúde e as pessoas. Defender a integralidade é defender antes de tudo que as práticas em saúde no SUS sejam sempre intersubjetivas, nas quais profissionais de saúde se relacionem com sujeitos, e não com objetos. Práticas intersubjetivas envolvem necessariamente uma dimensão dialógica. Isso confere às práticas de saúde um caráter de prática de conversação 4, na qual nós, profissionais de saúde, utilizamos nossos conhecimentos para identificar as necessidades de ações e serviços de saúde de cada sujeito com o qual nos relacionamos, para reconhecer amplamente os conjuntos de ações que podemos pôr em prática (incluindo ações como o aconselhamento e as chamadas práticas de educação em saúde) para responder as necessidades que apreendemos. Mais do que isso, defender a integralidade nas práticas é defender que nossa oferta de ações deve estar sintonizada com o contexto específico de cada encontro. Analisemos com mais cuidado cada um desses pontos.

Sujeitos têm modos de andar a vida, para usar a expressão de Canguilhem 5 , modos de andar a vida que se modificam (Canguilhem diria talvez, que se estreitam) pela ocorrência de uma doença. É claro que os modos de andar a vida não são escolhas das pessoas, mas emergem do próprio modo como a vida se produz coletivamente. O modo de andar a vida de um sujeito não pode ser compreendido como dissociado do modo como a vida anda num certo lugar, aonde ele vive. Mas cada sujeito apresen- 
ta singularidades que se expressam no seu modo de andar a vida.

Nós, os profissionais de saúde, detemos um vasto conhecimento sobre as doenças e os sofrimentos por elas causados, bem como sobre um certo número de ações capazes de interferir em algum grau sobre o modo de andar a vida estreitado pela doença. É esse conhecimento que nos permite atuar diante de um sofrimento assistencial. Mas, na perspectiva da integralidade, não devemos reduzir um sujeito à doença que lhe provoca sofrimento. Ao contrário, manter a perspectiva da intersubjetividade significa que devemos levar em conta, além dos nossos conhecimentos sobre as doenças, o conhecimento (que não necessariamente temos) sobre os modos de andar a vida daqueles com quem interagimos nos serviços de saúde. Isso implica a busca de construir, a partir do diálogo com o outro, projetos terapêuticos individualizados.

Mas nossos conhecimentos das doenças nos permitem em algumas situações intervir mesmo antes que ela suscite um sofrimento manifesto. Tais conhecimentos nos possibilitam identificar necessidades de ações e serviços não necessariamente demandadas pelos sujeitos. É claro que, na perspectiva da integralidade, não podemos deixar de levar em conta o significado que nossas recomendações de cunho preventivo podem ter no modo de andar a vida dos sujeitos. Ou seja, os projetos terapêuticos individuados, na perspectiva da integralidade, levam em conta também as ações voltadas para a prevenção.

Os projetos terapêuticos assim entendidos não são produto da simples aplicação dos conhecimentos sobre a doença. Na perspectiva da integralidade, eles emergem do diálogo (e porque não falar, da negociação) entre profissionais de saúde e os usuários dos serviços de saúde. A característica chave para a existência desse diálogo é a capacidade de compreender o contexto específico dos diferentes encontros. Compreensão que envolve por parte dos profissionais o esforço de selecionar num encontro os elementos relevantes para a elaboração do projeto terapêutico, tanto os evocados por ele com base em seus conhecimentos, quanto os trazidos pelo outro a partir de seus sofrimentos, de suas expectativas, de seus temores e de seus desejos.

Note-se que não se trata de apreender tudo; não se trata de uma postura holística. Trata-se mais de um exercício de seleção negociada do que é relevante para a construção de um projeto de intervenção (ou melhor, de um projeto terapêutico) capaz de dar oportunamente respostas ao conjunto de necessidades de ações e serviços de saúde 6 .

Alguns podem considerar que tal visão é utópica. Contudo, aqui e acolá uma série de propostas de mudança nas práticas e nos arranjos dos serviços caminham no sentido de concretização da integralidade. E uma série de experiências já concretizam essa aparente utopia. A idéia de que nenhuma pessoa que entra num serviço de saúde deve sair dele sem alguma resposta concreta desse serviço, idéia chave nas propostas de acolhimento, as teses que enfatizam a necessidade de uma escuta atenta por parte de todos os profissionais que atuam nos serviços de saúde (do segurança ao médico), as flexibilizações das rotinas sobre os fluxos dos usuários nos serviços de saúde de modo a permitir o desenho de um fluxo negociado para cada pessoa, as idéias de clínica ampliada, enfim, uma série de idéias e propostas têm sido formuladas e experimentadas em vários locais. Como também há muitos profissionais que, mesmo sem uma formulação teórica da proposta, ou mesmo sem utilizar o termo, praticam a integralidade no seu cotidiano.

\section{Resumo}

O artigo faz uma reflexão sobre as manifestações ou os signos da integralidade na prática em saúde, buscando facilitar o reconhecimento de experiências que estejam avançando e permitir que elas sejam posteriormente analisadas. Pretende também contribuir para que cada vez mais atores se engajem na construção de práticas pautadas pela integralidade. Parte-se do princípio de que o que caracteriza a integralidade é a apreensão ampliada das necessidades e a habilidade de re- conhecer a adequação da oferta ao contexto específico da situação no qual se dá o encontro do sujeito com a equipe de saúde; e defender a integralidade nas práticas é defender que a oferta de ações de saúde deva estar sintonizada com o contexto específico de cada encontro.

Atenção Integral à Saúde; Prática Profissional; Serviços de Saúde 


\section{Referências}

1. Mattos RA. Os sentidos da integralidade: algumas reflexões acerca de valores que merecem ser defendidos. In: Pinheiro R, Mattos RA, organizadores. Os sentidos da integralidade na atenção e no cuidado à saúde. Rio de Janeiro: Instituto de Medicina Social, Universidade do Estado do Rio de Janeiro/ABRASCO; 2001, p. 39-64.

2. Ministério da Saúde. Programa de Atenção Básica. Brasília: Ministério da Saúde; 2001.

3. Guedes AEL. O incentivo às carências nutricionais (ICCN): os desafios à integração de programas e à integralidade de ações de nutrição nas práticas de saúde [Tese de Doutorado]. Rio de Janeiro: Instituto de Medicina Social, Universidade do Estado do Rio de Janeiro; 2002.
4. Teixeira R. O acolhimento num serviço de saúde como entendido como uma rede de conversação. In: Pinheiro R, Mattos RA, organizadores. Construção da integralidade. Cotidiano, saberes e práticas em saúde. Rio de Janeiro: Instituto de Medicina Social, Universidade do Estado do Rio de Janeiro/ABRASCO; 2003. p. 89-112.

5. Canguilhem, G. O normal e o patológico. Rio de Janeiro: Forense; 1978.

6. Silva Jr. AG, Merhy EE, Carvalho LC. Refletindo sobre o ato de cuidar da saúde. In: Pinheiro R, Mattos RA, organizadores. Construção da integralidade. Cotidiano, saberes e práticas em saúde. Rio de Janeiro: Instituto de Medicina Social, Universidade do Estado do Rio de Janeiro/ABRASCO; 2003. p. 113-28.

Recebido em 14/Jun/2004

Aprovado em 15/Jun/2004 